\title{
Epithelial to mesenchymal transition and HPV infection in squamous cell oropharyngeal carcinomas: the papillophar study
}

Marine Lefevre ${ }^{1}$, Alexandra Rousseau², Thomas Rayon ${ }^{2}$, Véronique Dalstein $^{3}$, Christine Clavel ${ }^{3}$, Agnès Beby-Defaux ${ }^{4}$, Jean-Luc Pretet ${ }^{5}$, Patrick Soussan ${ }^{6,7}$, Myriam Polette ${ }^{3}$, Jean Lacau Saint Guily ${ }^{8}$, Philippe Birembaut ${ }^{\star 3}$ and the Papillophar Study Group 9

${ }^{1}$ Laboratoire d'Anatomie Pathologique, Hôpital Tenon, 4, rue de la Chine, Université Pierre et Marie Curie Paris 6,75050 Paris, France; ${ }^{2}$ AP-HP Hôpital Saint Antoine, URC-Est, 184 rue du Faubourg Saint Antoine, Université Pierre et Marie Curie Paris 6, 75012 Paris, France; ${ }^{3}$ INSERM UMR-S 903, Université de Reims-Champagne-Ardenne and Laboratoire de Biopathologie CHU Maison Blanche, 45, rue Cognacq-Jay, 51100 Reims, France; ${ }^{4}$ Unité de Virologie, CHU de POITIERS, Faculté de Médecine de Poitiers Equipe émergente 2RCT, Université de Poitiers, Poitiers 86000, France; ${ }^{5}$ Université de Franche Comté, COMUE UBFC, 25000 Besancon, France; ' ${ }^{2}$ aboratoire de Virologie, Hôpital Tenon, 4, rue de la Chine, 75050 Paris, France; ${ }^{7}$ INSERM U1135 Université Pierre et Marie Curie, Paris 6, Paris 75000, France and ${ }^{8}$ AP-HP Hôpital Tenon, Service d'Oto-Rhino-Laryngologie, 4, rue de la Chine, Université Pierre et Marie Curie Paris 6, 75050 Paris, France

Background: Human Papillomavirus (HPV) infection is recognised as aetiological factor of carcinogenesis in oropharyngeal squamous cell carcinomas (OPC). HPV-related OPC respond better to treatments and have a significantly favourable outcome. Epithelial to mesenchymal transition (EMT) implicated in tumour invasion, is a hallmark of a poor prognosis in carcinomas.

Methods: We have studied the relationship of EMT markers (E-cadherin, $\beta$-catenin and vimentin) with HPV infection (DNA and E6/ E7 mRNA detection), p16 ${ }^{\text {INK4a }}$ expression and survival outcomes in a cohort of 296 patients with OPC.

Results: Among the 296 OPSSC, $26 \%$ were HPV positive, $20.3 \%$ had overt EMT ( $>25 \%$ of vimentin positive tumour cells). Lower E-cadherin expression was associated with a higher risk of distant metastasis in univariate $(P=0.0110)$ and multivariate analyses (hazard ratios $(H R)=6.86(1.98 ; 23.84)$ ). Vimentin expression tends towards worse metastasis-free survival (MFS; HR = 2.53 (1.00; 6.41)) and was an independent prognostic factor of progression-free survival (HR=1.55 (1.03; 2.34)).

Conclusions: There was a non significant association of EMT with HPV status. This may be explained by a mixed subpopulation of patients HPV positive with associated risk factors (HPV, tobacco and alcohol). Thus, the detection of EMT in OPC represents another reliable approach in the prognosis and the management of OPC whatever their HPV status.

Tobacco and alcohol consumption are the most well known risk factors for the development of oropharyngeal squamous cell carcinomas (OPC; Hashibe et al, 2009). However, Human Papillomavirus (HPV) infection, particularly type 16, is now recognised as a major aetiological factor of carcinogenesis in these cancers (Kreimer et al, 2005; Syrjanen and Syrjanen, 2013). The detection of an active HPV infection is variably appreciated in the literature. It is now admitted that the presence of both HPV DNA and mRNA encoding HPV oncogenic proteins E6/7 in tumours clearly identifies a clinically active infection involved in

*Correspondence: Professor P Birembaut; E-mail: pbirembaut@chu-reims.fr

${ }^{9} \mathrm{~A}$ full list of members appear above the reference section.

Received 5 September 2016; revised 25 November 2016; accepted 5 December 2016; published online 10 January 2017

(c) 2017 Cancer Research UK. All rights reserved 0007-0920/17 
carcinogenesis (Jung et al, 2010; Holzinger et al, 2012). HPVrelated OPC are frequently associated with lymph node metastases (Smith et al, 2004; Joo et al, 2012). However, they respond better to treatments (surgery, radiotherapy and chemotherapy) than tumours associated with traditional risk factors (Ragin and Taioli, 2007; Fakhry et $a l, 2008)$ and generally they have a significantly favourable survival outcome. At the present time, the number of these tumours is dramatically increasing, reaching up to $72 \%$ in some countries, which led some authors to use the term of a growing epidemic (Hammarstedt et al, 2006; Aulock et al, 2010; Hong et al, 2010; Marur et al, 2010; Chatuverdi et al, 2011).

Epithelial to mesenchymal transition (EMT) is characterised by diminished epithelial characteristics such as a reorganisation of intercellular junctions, including E-cadherin and $\beta$-catenin expression, and enhanced mesenchymal attributes such as increased expression of vimentin, fibronectin and proteolytic enzymes. EMT has been described in embryologic morphogenesis, fibrosis and lately in tumour invasion and metastasis processes (Thiery, 2002; Kalluri and Weinberg, 2009). In carcinomas, EMT is also associated to cancer stem cell properties (Mani et al, 2008). EMT has been reported in head and neck squamous cell carcinomas (HNSSC) and generally associated with a poor prognosis (Andrews et al, 1997; Zidar et al, 2008; Kojc et al, 2009; Huber et al, 2011; Mendelsohn et al, 2012; Zhao et al, 2012; Kwon et al, 2013; Zhang et al, 2013; Hatakeyama et al, 2014; Pectasides et al, 2014; Cappellesso et al, 2015; Jensen et al, 2015; Schrader et al, 2015; Wakisaka et al, 2015). Moreover, EMT predicts drug resistance in HNSSC cell lines (Frederick et al, 2007). However, the literature investigating the expression of EMT markers and their correlation with HPV status and prognosis is poor in OPC with limited series of patients (Mendelsohn et al, 2012; Hatakeyama et al, 2014; Wakisaka et al, 2015).

Thus, the aim of the present work is to study the relationship of EMT markers, with HPV infection (DNA and RNA) and survival outcome in a large cohort of 296 OPC in well clinically characterised patients, to get new insights in the prognosis of OPC.

\section{MATERIALS AND METHODS}

Patients and tumours. The PAPILLOPHAR study is a prospective cohort of 340 adult patients with OPC recruited from May 2009 to April 2012 in 14 French centres. Patients were followed according to the recommendations of the French Otolaryngology, Head and Neck Surgery Society: every 2 months during the first year and every 3 months during the second year. All patients provided written informed consent. The study was approved by the ethical committee (Comité de Protection des Personnes Ile-deFrance III), and French data protection authority (Commission Nationale de l'Informatique et des Libertés). Clinical Trials.gov was NCT00918710.

HPV status. High risk HPV DNA and E6/E7 mRNA were detected from frozen biopsies using the INNO-LIPA kit (Innogenetics, Gent, Belgium) and the NucliSENS EasyQ kit (bioMérieux, Marcy-l'Etoile, France), respectively. E6/E7 mRNA detection was performed in DNA positive tumours. Positive HPV status was defined as both positive DNA and E6/E7 mRNA detection.

Immunohistochemistry. Serial tissue sections of $4-\mu$ m-thick were performed on formalin-fixed paraffin-embedded blocks of OPC, at initial diagnosis. Immunohistochemistry was performed with antibodies against cytokeratins (Dako Glostrup, Denmark, Ref $\mathrm{H} 3515$, dilution 1: 50, clone AE1/AE3), E-cadherin (Dako Ref M3612 dilution: 1: 50, clone NCH-38), $\beta$-catenin (Cell marque Ref 7604242 pre-diluted ready to use, clone 14), vimentin (Dako, Ref MO725, dilution 1:600, clone V9) for EMT and antibody against p16 ${ }^{\text {INK4a }}$ (Ventana Cintec p16 Histology Ref 805-4713, pre-diluted ready to use, clone E6H4), classically considered as a marker of an active HPV infection in the literature. Subsequent steps were performed with the ultraView universal DAB detection kit (Ventana). Ventana Benchmark XT autostainer (Ventana Medical Systems, Inc., Tucson, AZ, USA) was used for all these immunohistochemical studies.

Histological evaluation of the tumours and scoring of the results for immunohistochemical detection of keratins, vimentin, E-cadherin and $\beta$-catenin were centralised and assessed by two pathologists who had no knowledge of the clinical data. When a discrepancy was found between the two investigators, a consensus was reached via simultaneous examination using a double-headed microscope.

Tumour differentiation was evaluated according to the detection of intercellular bridges and keratinisation with variable 'pearl' formation, and graded into well-, moderately and poorly differentiated squamous cell carcinomas according to the Classification of Head and Neck tumours of the World Health Organization.

EMT is defined by a loss of epithelial markers such as cytokeratins and cell adhesion molecules and vimentin expression. Scoring for immunohistochemistry of cytokeratins, E-cadherin and $\beta$-catenin was as follows: $0=$ no detection, $1=$ detection in $<10 \%$ of tumour cells, $2=$ detection in $10-25 \%$ of tumour cells, $3=$ detection in $25-50 \%$ of tumour cells, $4=$ detection in $>50 \%$ of tumour cells. Cytokeratins were detected in the cytoplasm of tumour cells and we took into account cell membrane staining of epithelial cell adhesion molecules, E-cadherin and $\beta$-catenin, for the evaluation of their immunohistochemical detection. Nuclear detection of $\beta$-catenin, a good marker of EMT as a co-transcription factor of genes implicated in this process (Lamouille et al, 2014), was also specified in the results. In addition, for E-cadherin and $\beta$-catenin, the intensity of staining was graded as follows: 1 for background staining, 2 for weak staining, 3 for moderate staining and 4 for strong staining. Subsequently, for these two markers, both scores were multiplied resulting in the final expression score ranging from 0 to 16 .

Vimentin expression is associated with changes in cell shape, motility and adhesion during EMT (Mendez et al, 2010) and has been largely used in the literature to identify tumour cells undergoing EMT with a fibroblastoid phenotype in carcinomas (Gabbiani et al, 1981; Klymkowsky and Savagner, 2009, Zeisberg and Neilsson, 2009 and particularly in OPC (Hatakeyama et al, 2014; Schrader et al, 2015; Wakasika et al, 2015). The percentage of vimentin expression by cancer cells within the tumour is a relevant prognostic marker (Dauphin et al, 2013; Hatakeyama et al, 2014; Wakasika et al, 2015). Thus, EMT was graded according to cytoplasmic vimentin expression scoring as follows: $0=$ no EMT for vimentin score from 0 to $10 \%, 1=$ mild EMT for vimentin score between 11 and $25 \%$, $2=$ overt EMT for vimentin score above $25 \%$.

p16 ${ }^{\mathrm{INK} 4 \mathrm{a}}$ was considered as positive when $>80 \%$ tumour cells were stained with a strong cytoplasmic and nuclear labelling.

Study endpoints. Metastasis-free survival (MFS) was defined as the time from the date of OPC diagnosis to the date of distant metastases. Progression-free survival (PFS) was defined as the time from the date of OPC diagnosis to the date of first documented relapse, categorised as loco-regional disease (tumour at the primary site or regional nodes) or the date of distant metastasis or the date of cancer-related death. Overall survival (OS) was calculated as the time from the date of OPC diagnosis to the date of cancer-related death.

Statistical analysis. In agreement with epidemiological data, tobacco smoking was classified according to current status and duration of cessation among former users into three groups: (1) never-smokers ( $<100$ cigarettes in lifetime); (2) long-duration former smokers ( $\geqslant 10$ year-cessation); and (3) current smokers or recent former smokers ( $<10$ year-cessation). Pack-years $(\mathrm{P} / \mathrm{Y})$ were also estimated for current and former smokers for $<10$ years and classified as below or above the median (40 P/Y). Alcohol 
consumption was classified into: (1) never- and occasional drinkers $(<1$ drink per day) and long-duration former drinkers $(\geqslant 10$ yearcessation); and (2) current and short-term ( $<10$ years) drinkers. The large number of treatment combinations used in Papillophar was classified according to initial treatment into: (1) up-front surgery; (2) up-front radiotherapy; (3) induction chemotherapy. Owing to the limited numbers of the (0-8) E-cadherin expression level, (0-8) and (8-12) levels have been gathered for prognosis analysis.

Qualitative variables were expressed as percentage and effective and compared using $\chi^{2}$ test or Fisher exact test when appropriate. Continuous variables were expressed as mean and s.d. Missing values were not replaced.

Follow-up was truncated at 30 months. Survival curves were estimated using Kaplan-Meier method (Greenwood variance). Prognostic value of EMT markers was evaluated in univariate analysis using Cox proportional hazard model. Multivariate analyses were performed when $P$-value was $\leqslant 0.20$ in univariate analysis. Multivariate analyses were adjusted, as appropriate, for all variables shown in univariate analyses, including HPV status. HR and corresponding 95\% confidence intervals (CIs) were computed. $P$-value $<0.05$ was considered to achieve statistical significance. Analyses were performed using SAS V.9.3 software (SAS Institute, Cary, NC, USA).

\section{RESULTS}

Among the 340 patients included in the PAPILLOPHAR study, 296 patients with OPC have been investigated for EMT markers. Baseline characteristics of the patients are shown in Table 1.

Out of 296 patients, 77 (26.01\%) were HPV DNA and HPV E6/ E7 mRNA positive. Out of them, 28 (36.36\%) were current smokers or recent former smokers ( $<10$ year-cessation).

Multivariate analyses (without taking in account EMT markers) confirmed that HPV status is an independent prognostic factor for PFS $(\mathrm{HR}=0.41(0.23 ; 0.74))$, OS $(\mathrm{HR}=0.19(0.09 ; 0.43))$, but not for MFS $(P=0.15$, data not shown).

Histology and immunohistochemical findings. (Table 1) Diagnosis of basaloid tumour was more frequent in HPV positive than in HPV negative tumours $(15,6 \%$ vs $5,5 \%, P=0.0052)$ and lack of differentiation of the OPC was more frequent in HPV positive than in HPV negative tumours ( $75.3 \%$ vs $40.6 \%, P<0.0001)$. Cytokeratins were consistently present in tumour cells. E-cadherin and $\beta$-catenin were largely expressed at the tumour cell membranes (Figures 1C and D), with scores of $12-16$ in $90.5 \%$ of cases for E-cadherin and scores of $12-16$ in $85.5 \%$ for $\beta$-catenin. Nuclear $\beta$-catenin was detected in $3.7 \%$ of OPC, all these cases expressing vimentin in $>25 \%$ of tumour cells. Neither E-cadherin nor $\beta$-catenin expressions were related to HPV status (data not shown). Vimentin expression was observed in tumour cells, principally at invasion fronts of the tumour clusters and individual invasive cells (Figure 1B). Vimentin was frequently co-expressed in E-cadherin positive cells, but was consistently detected in E-cadherin negative tumour cells. Vimentin was detected in 175 tumours including 81 $(27.4 \%) \leqslant 10 \%$ of positive cells, 34 (11.5\%) between 10 and $25 \%, 23$ (7.8\%) between 25 and $50 \%$ and 37 (12.5\%) more than $50 \%$ of positive cells. Considering vimentin expression, EMT was not significantly related to HPV status (no EMT $=64.8 \%$, mild EMT $=12.8 \%$, overt $\mathrm{EMT}=22.4 \%$ in HPV negative tumours $v$ s $77.9,7.8$ and $14.3 \%$ in HPV-positive tumours, respectively, $P=0.1139$ ).

EMT was not related to basaloid tumours $(P=0.2086)$ and overt EMT was more frequent among poorly differentiated tumour than in moderately or well differentiated tumour (27.2, 15.2 and 9.1, respectively, $P=0.0491)$. p16 ${ }^{\mathrm{INK} 4 \mathrm{a}}$ was considered as positive in one third of OPC (Figure 1A). There was an association between $16^{\mathrm{INK} 4 \mathrm{a}}$ detection and EMT: overt EMT was less frequent in $\mathrm{p} 16^{\mathrm{INK} 4 \mathrm{a}}$ positive tumours than in negative tumours ( $166^{\mathrm{INK} 4 \mathrm{a}}$ negative: no EMT $=62.56 \%$, mild EMT $=13.85 \%$, overt EMT $=23.59 \%$ vs $16^{\mathrm{INK} 4 \mathrm{a}}$ positive: no EMT 79.21\%, mild EMT 6.93\%, overt EMT $=13.86 \%$, $P=0.0137)$. However, it has to be emphasised that 24 tumours positive for $\mathrm{p} 16^{\mathrm{INK} 4 \mathrm{a}}$ were HPV negative.

Prognostic value of $\beta$-catenin and E-cadherin. In univariate analysis, $\beta$-catenin and nuclear $\beta$-catenin were not related to the survival outcomes. Lower level of E-cadherin expression was associated with higher risk of distant metastasis in univariate analysis $(P=0.0110$, Figure $2 \mathrm{C})$, and this was confirmed in multivariate analysis $(\mathrm{HR}=6.86(1.98 ; 23.84)$, Table 2$)$. E-cadherin expression was not related with the other endpoints.

Prognostic value of EMT considering vimentin expression. In univariate analysis, overt EMT was associated with higher risk of distant metastasis $(P=0.0173)$. As mild EMT showed similar risk of metastasis than the absence of EMT (HR $=2.16(0.59 ; 7.93))$, the two levels were pooled for further analysis. Univariate and multivariate analysis are shown in Table 2 and survival curves in Figure 2A. In multivariate analysis, higher risk of metastasis associated with overt EMT was lowered and at the limit of significant threshold $(P=0.0511)$. HPV status was not related with MFS and there was no interaction between HPV status and EMT $(P=0.61)$.

Overt EMT was associated with higher risk of progression in univariate $(P=0.0386$, Figure $2 \mathrm{~B})$ and in multivariate analyses but was not related to the other outcomes.

Prognostic value of EMT combined with HPV status. If we combined both EMT markers (vimentin expression and downregulation of E-cadherin) with HPV status, there was a significant worse MFS when overt EMT expression was detected in HPVnegative OPC and when down-regulation of E-cadherin was present in both HPV-positive and -negative OPC, in multivariate analyses (Table 3).

\section{DISCUSSION}

The present prospective study on 296 patients confirms the numerous data of the literature reporting the detection of HPV infection as a good independent prognostic marker in OPC (Fakhry et al, 2008; Jung et al, 2010; Holzinger et al, 2012; Hatakeyama et al, 2014; Umbrett et al, 2014). Indeed, HPV status is an independent prognostic factor for PFS. Thus, HPV detection represents a good approach to evaluate the outcome of OPC.

The role of EMT in the prognosis of HNSSC, especially OPC, has also been well studied using various different approaches: expression of transcriptional factors implicated in EMT such as Snail (Zidar et al, 2008; Kojc et al, 2009; Mendelsohn et al, 2012), Slug (Kojc et al, 2009; Zhang et al, 2013; Cappellasso et al, 2015), Twist (Kojc et al, 2009; Kwon et al, 2013), SIP-1 (Kojc et al, 2009) and ZEB1 (Jensen et al, 2015), down-regulation of the E-cadherin/ catenin complex (Andrews et al, 1997; Huber et al, 2011; Zhao et al, 2012; Kwon et al, 2013; Hatakeyama et al, 2014; Pectasides et al, 2014; Wakasika et al, 2015; Cappellasso et al, 2015) and expression of vimentin (Hatakeyama et al, 2014; Schrader et al, 2015; Wakasika et al, 2015) with different thresholds. Most of these studies reported a worse outcome associated with EMT with poor PFS (Schrader et al, 2015), disease free survival (DFS; Mendelsohn et al, 2012; Cappellasso et al, 2015), Jensen et al, 2015 and OS (Kwon et al, 2013; Hatakeyama et al, 2014; Pectasides et al, 2014; Jensen et al, 2015; Schrader et al, 2015). Nevertheless, considering the DFS, Wakasika et al (2015) stated that EMT in OPC was not 


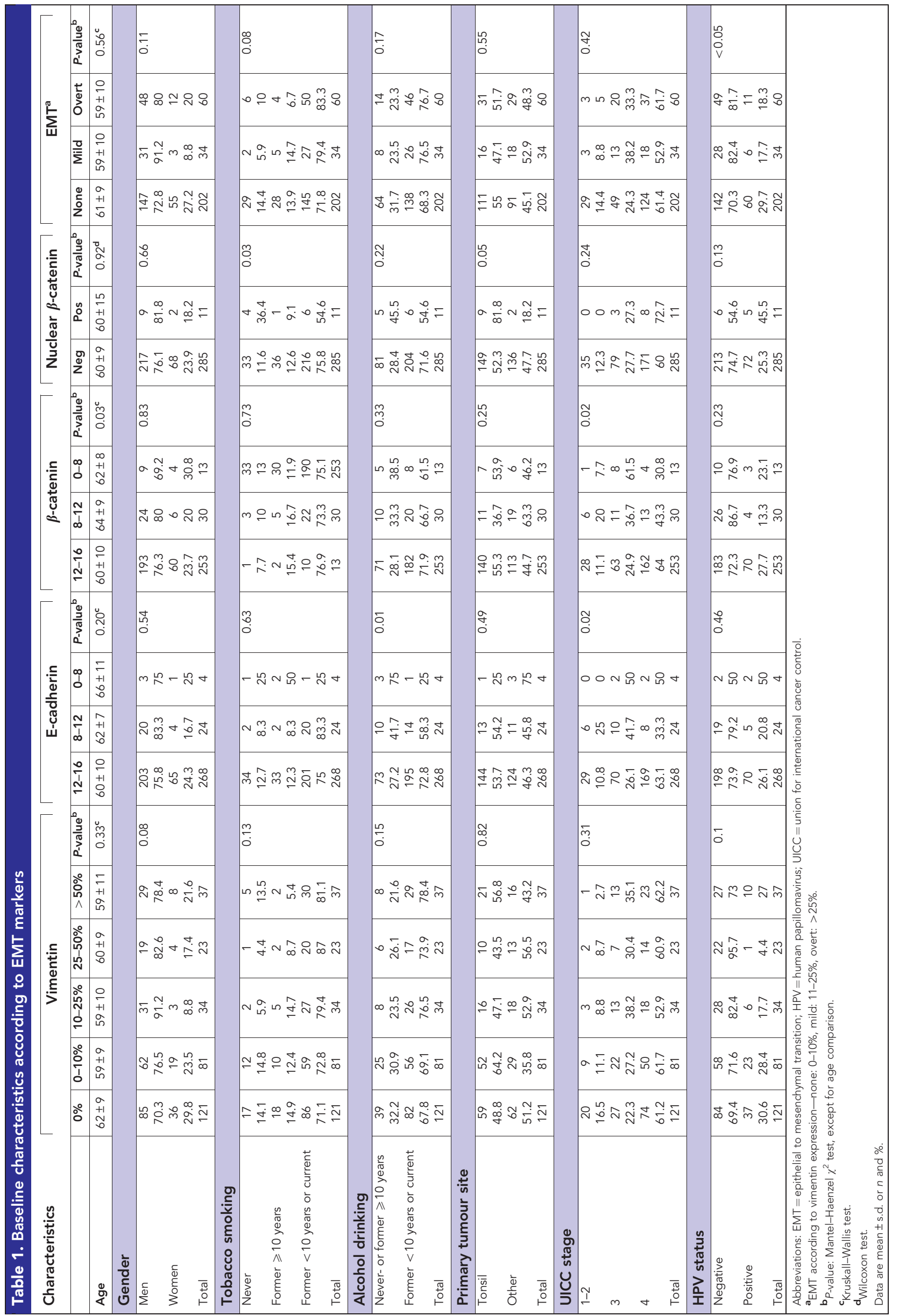



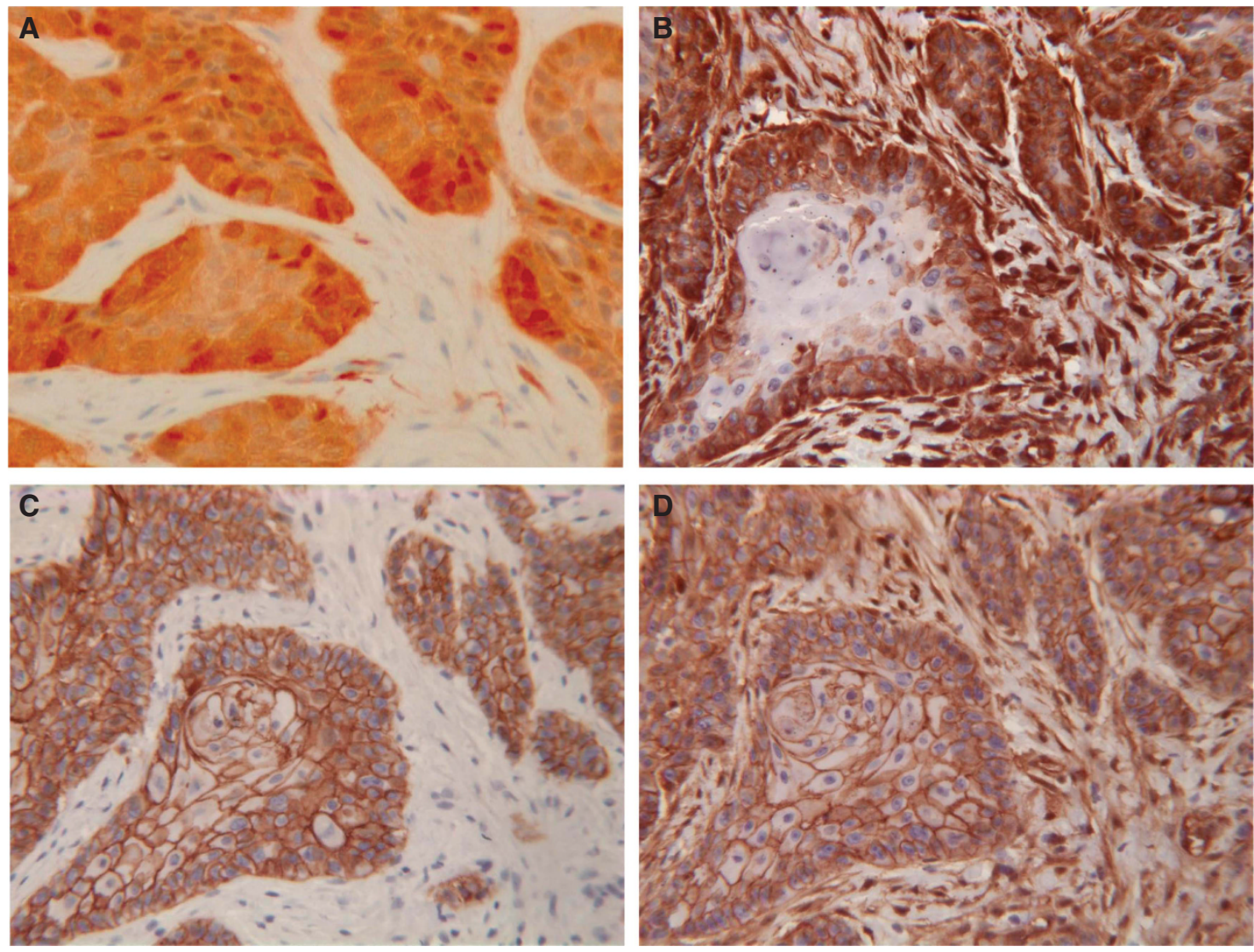

Figure 1. Expression of $\mathrm{p} 16^{\text {ink4a }}$ in tumour cells of OPC (A). Vimentin is expressed in tumour clusters at the invasion front (B) while E-cadherin (C) and $\beta$-catenin (D) are still present in tumour cell membranes in the same territory of an OPC $(\times 250)$.

involved as a specific prognostic marker, but was only significantly associated with lymph node metastases. In our present work, the expression and particularly the loss of cell adhesion molecules E-cadherin and $\beta$-catenin, were not reliable markers for the OS of OPC, in agreement with the findings of Andrews et al (1997) using similar thresholds. These molecules were present on cancer cell membranes in a large majority of OPC whatever their stage and outcome. However, contrary to the data of Andrews et al (1997), in multivariate analysis, lower E-cadherin expression with a score $<12$ had a higher risk of metastasis. These latter results confirm the recent data of Hatakeyama et al (2014) and the meta-analysis of Zhao et al (2012) concluding that aberrant E-cadherin expression is a poor prognostic factor in HNSSC. In another way, vimentin expression in $>25 \%$ of cancer cells was a relevant hallmark of tumour aggressiveness, generally associated with poor differentiation in OPC. Indeed, in our study, we found that vimentin expression was an independent prognostic factor of PFS and at the limit of significance for MS. There was a 2.53-fold higher risk of metastasis when more than $25 \%$ of cancer cells expressed vimentin. Thus, in our experience, EMT evaluated by E-cadherin and vimentin expression, is a reliable prognostic marker of poor outcome in OPC.

The relationship between HPV infection indicating a good prognosis, and EMT classically associated with a more aggressive behaviour of tumour cells, is more complex. The role of HPV oncogenic proteins in the physiopathology of EMT has also been recently proposed. Jung et al (2013) demonstrated that HPV16 E6 and E7 induce expression of transcriptional factors Slug, Twist, ZEB1 and ZEB2 involved in EMT. Hellner et al (2009) showed that expression of HPV16 E7 oncoprotein in normal epithelial cells caused increased levels of vimentin and fibronectin, whereas E-cadherin expression decreased. Laurson et al (2010) reported an epigenetic repression of E-cadherin by HPV16 E7. Boulenouar et al
(2010) described the effects of HPV16 E5, E6 and E7 proteins impairing E-cadherin expression in trophoblastic cells. In another way, it has also been described a high propensity for EMT induced by $\mathrm{EGF} / \mathrm{TGF} \beta 1$, in $\mathrm{p} 16^{\mathrm{INK} 4 \mathrm{a}}$ positive OPC cells compared to p16 ${ }^{\text {ink4a }}$ negative cells (Umbrett et al, 2014) and a switch from FGFR2b to FGFR2c and EMT induced by HPV16 E5 (Ranieri et al, 2015). In vivo, two recent papers with limited series of cases, 79 patients (Hatakeyama et al, 2014) and 53 patients (Wakisaka et al, 2015) showed a paradoxical association of HPV infection and EMT in OPC. In both studies, HPV infection was assessed by DNA detection using PCR, associated with $\mathrm{p} 16^{\mathrm{INK} 4 \mathrm{a}}$ detection (Hatakeyama et al, 2014). The authors considered that EMT was only involved in the local lymph node metastatic process, frequently observed in HPV-related OPC (Smith et al, 2004; Joo et al, 2012). A third study on 42 cases, using HPV detection by in situ hybridisation, also provided evidence of Snail role as a molecular marker for regional metastasis in HNSSCs (Mendelsohn et al, 2012). But Snail positivity appeared independent of HPV16 detection and $\mathrm{p} 16^{\mathrm{INK} 4 \mathrm{a}}$ expression. Contrary to all these in vivo and in vitro data, in our cohort of 296 patients, there was a significant relation between $\mathrm{p} 16^{\mathrm{INK} 4 \mathrm{a}}$ negative tumours and EMT. However, it has to be emphasised that 24 out 219 HPV negative carcinomas (10.9\%) expressed $\mathrm{p} 16^{\mathrm{INK} 4 \mathrm{a}}$. Indeed, $\mathrm{p} 16^{\mathrm{INK} 4 \mathrm{a}}$ expression alone represents a less relevant proof of active HPV infection than the combined detection of DNA and E6/E7 mRNA. Using this latter approach, we did not find any significant relation between the absence of an active HPV infection and EMT $(P=0.1139)$. This non significant association of EMT with HPV status may be explained by a mixed subpopulation with associated different risk factors (HPV, tobacco and alcohol) which may interfere in the tumorigenic pathways of these carcinomas. Indeed, 28 patients (36.6\%) were smokers in our population of $77 \mathrm{HPV}$ positive 

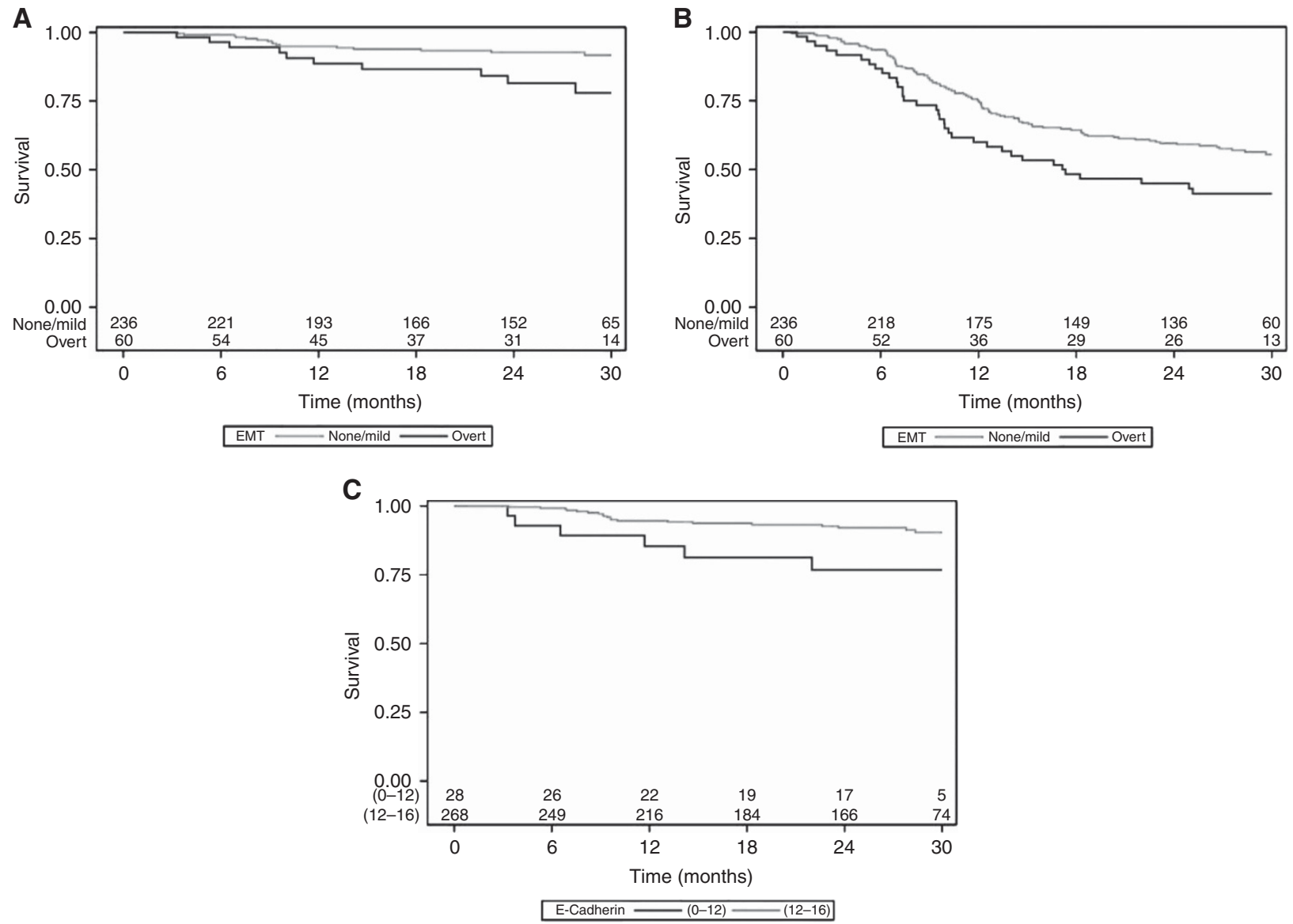

Figure 2. (A) Kaplan-Meier estimation of MFS according to EMT level. (B) Kaplan-Meier estimation of PFS according to EMT level. (C) KaplanMeier estimation of MFS according to E-Cadherin expression. The full colour version of this figure is available at British Journal of Cancer online.

Table 2. MFS and progression-free survival according to EMT markers

\begin{tabular}{|c|c|c|c|c|}
\hline Variable & $\begin{array}{l}\text { MFS univariate } \\
\text { analysis HR } \\
(95 \% \mathrm{Cl})^{\mathrm{a}}\end{array}$ & $\begin{array}{c}\text { MFS multivariate } \\
\text { analysis HR } \\
(95 \% \mathrm{Cl})^{\mathrm{b}}\end{array}$ & $\begin{array}{c}\text { PFS } \\
\text { univariate analysis HR } \\
(95 \% \mathrm{Cl})^{\mathrm{a}}\end{array}$ & $\begin{array}{c}\text { PFS } \\
\text { multivariate analysis HR } \\
(95 \% \mathrm{Cl})^{\mathrm{b}}\end{array}$ \\
\hline \multicolumn{5}{|l|}{ Vimentin } \\
\hline 0 & 1 & 1 & 1 & 1 \\
\hline (0-10\%) & $0.56(0.15 ; 2.14)$ & $0.66(0.16 ; 2.67)$ & $1.43(0.92 ; 2.22)$ & $0.66(0.16 ; 2.67)$ \\
\hline (10-25\%) & $1.77(0.46 ; 6.87)$ & $1.96(0.43 ; 9.00)$ & $1.50(0.83 ; 2.73)$ & $1.96(0.43 ; 9.00)$ \\
\hline (25-50\%) & $2.86(0.80 ; 10.23)$ & $3.40(0.84 ; 13.81)$ & $3.19(1.75 ; 5.80)$ & $3.40(0.84 ; 13.81)$ \\
\hline$>50 \%$ & $2.43(0.81 ; 7.31)$ & $2.10(0.63 ; 7.01)$ & $1.31(0.74 ; 2.29)$ & $2.10(0.63 ; 7.01)$ \\
\hline \multicolumn{5}{|l|}{ E-cadherin } \\
\hline$(12-16)$ & 1 & 1 & 1 & 1 \\
\hline$(0-12)$ & $3.72(1.35 ; 0.26)$ & $6.86(1.98 ; 23.84)$ & $1.08(0.60 ; 1.97)$ & $1.31(0.70 ; 2.46)$ \\
\hline \multicolumn{5}{|l|}{$\beta$-catenin } \\
\hline$(12-16)$ & 1 & 1 & 1 & 1 \\
\hline$(0-12)$ & $0.73(0.21 ; 2.56)$ & $1.16(0.31 ; 4.35)$ & $1.26(0.77 ; 2.06)$ & $1.58(0.93 ; 2.67)$ \\
\hline \multicolumn{5}{|c|}{ Nuclear $\beta$-catenin } \\
\hline Negative & 1 & 1 & 1 & 1 \\
\hline Positive & $2.42(0.50 ; 11.64)$ & $1.56(0.29 ; 8.43)$ & $1.23(0.48 ; 3.12)$ & $1.93(0.74 ; 5.09)$ \\
\hline \multicolumn{5}{|l|}{$\mathrm{EMT}^{\mathrm{c}}$} \\
\hline None or mild & 1 & - & 1 & 1 \\
\hline Overt & $2.77(1.20 ; 6.39)$ & $2.53(1.00 ; 6.41)$ & $1.52(1.02 ; 2.26)$ & $1.57(1.04 ; 2.37)$ \\
\hline \multicolumn{5}{|c|}{ 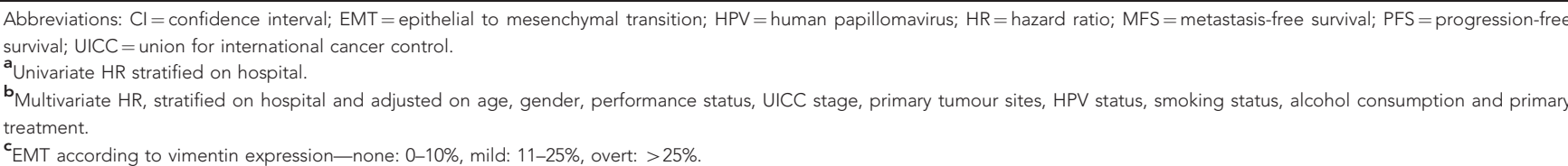 } \\
\hline
\end{tabular}


Table 3. MFS according to EMT markers combined with HPV status

\begin{tabular}{|c|c|c|}
\hline Combination & MFS univariate analysis $\mathrm{HR}(95 \% \mathrm{CI})^{a}$ & MFS multivariate analysis HR $(95 \% \mathrm{Cl})^{\mathrm{b}}$ \\
\hline \multicolumn{3}{|l|}{$\mathrm{EMT}^{\mathrm{c}}$ and HPV } \\
\hline $\begin{array}{l}\text { Without or mild EMT_-HPV neg } \\
\text { Without or mild EMT_-HPV pos } \\
\text { Overt EMT_-HPV negative } \\
\text { Overt EMT_-HPV positive }\end{array}$ & $\begin{array}{c}1 \\
1.31(0.46 ; 3.73) \\
3.21(1.19 ; 8.62) \\
2.56(0.53 ; 12.36)\end{array}$ & $\begin{array}{c}1 \\
3.10(0.90 ; 10.65) \\
3.15(1.08 ; 9.20) \\
4.07(0.64 ; 25.89)\end{array}$ \\
\hline \multicolumn{3}{|l|}{ E-cadherin and HPV } \\
\hline $\begin{array}{l}\text { E-cadherin (12-16)_HPV neg } \\
\text { E-cadherin (12-16)_HPV pos } \\
\text { E-cadherin (0-12)_HPV neg } \\
\text { E-cadherin (0-12)_HPV pos }\end{array}$ & $\begin{array}{c}1 \\
0.97(0.36 ; 2.59) \\
3.15(0.93 ; 10.66) \\
5.49(1.07 ; 28.09)\end{array}$ & $\begin{array}{c}1 \\
2.05(0.69 ; 6.14) \\
6.99(1.49 ; 32.81) \\
13.61(1.46 ; 126.7)\end{array}$ \\
\hline \multicolumn{3}{|c|}{ 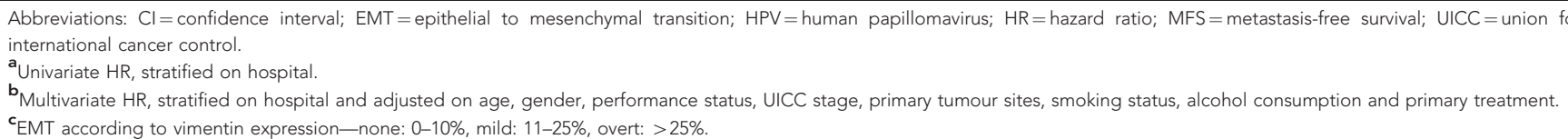 } \\
\hline
\end{tabular}

patients, and it has been well demonstrated that nicotine promotes EMT in HNSSC (Yu et al, 2012). Thus, our results emphasise the necessity to take in account other factors than HPV status such as EMT, for the prognosis of OPC.

In conclusion, our study confirms the data of literature on the good prognosis of HPV infection in OPC and points out EMT as an unfavourable marker of evolution in all these carcinomas. Of particular interest is that these two factors act independently, and when combined, they bring significant additional information on MFS of OPC. In consequence, the detection of EMT in OPC represents another reliable approach in the prognosis and eventually the management of these cancers (Graves et al, 2014) whatever their HPV status. These findings have particularly to be taken into account considering the different therapeutic protocols actually proposed for HPV positive OPC.

Research support. This study was funded by grants from the Programme Hospitalier de Recherche Clinique, French Ministry of Health (AOM 08104, AOM 11293).

\section{ACKNOWLEDGEMENTS}

The sponsor was Assistance Publique- Hôpitaux de Paris (Département de la Recherche Clinique et du Développement, Ile de France). We thank Mireille Toy Miou and France Guyot-Rousseau from the Clinical Research Unit of East of Paris (URC-Est), Saint Antoine University Hospital (Assistance Publique-Hôpitaux de Paris and Pierre-et-Marie Curie UniversityParis 6) for study coordination and logistics, Judith Leblanc from the Clinical Research Center of East of Paris (CRC-Est), Saint Antoine University Hospital (Assistance Publique-Hôpitaux de Paris) for her logistic support and Silvia Franceschi for helpful discussion.

\section{CONFLICT OF INTEREST}

The authors declare no conflict of interest.

\section{PAPILLOPHAR STUDY GROUP}

G Agius, S Albert, E Babin, C Bach, JM Badet, C Badoual, AC Baglin, B Barry, B Baujat, C Bertolus, K Blanc-Fournier, E Cassagneau, C Debry, D de Raucourt, MD Diebold, X Dufour, M Hourseau, B Kantelip, R Lacave, E Lechapt, J Lerat, M Lesnik, P Levillain, O Malard, A Mechine, JC Merol, H Mirghani,
S Morinière, C Mougin, S Périé, C Rousselot, P Schultz, T Simon and A Touzé.

\section{REFERENCES}

Andrews NA, Jones AS, Helliwell TR, Kinsella AR (1997) Expression of the E-cadherin-catenin cell adhesion complex in primary squamous cell carcinomas of the head and neck and their nodal metastases. Br J Cancer 75: $1474-1480$

Aulock A, Hislop G, Badjik C, Poh C, Zhang L, Rosin M (2010) Trends in oropharyngeal and oral cavity cancer incidence of human papillomavirus (HPV)-related and HPV-unrelated sites in a multicultural population: the British Columbia experience. Cancer 116: 2635-2644.

Boulenouar S, Weyn C, Ven Noppen M, Moussa Ali M, Favre M, Delvenne PO, Bex F, Noël A, Englert Y, Fontaine V (2010) Effects of HPV16 E5, E6 and E7 proteins on survival, adhesion, migration and invasion of trophoblastic cells. Carcinogenesis 31: 473-480.

Cappellesso R, Marioni G, Crescenzi M, Giacomelli L, Guzzardo V, Mussato A, Staffieri A, Martini A, Blandamura S, Fassino A (2015) The prognostic role of the epithelial-mesenchymal transition markers E-cadherin and Slug in laryngeal squamous cell carcinoma. Histopathology 67: 491-500.

Chatuverdi AK, Engels EA, Pfeiffer RM, Hernandez BY, Xiao W, Kim E, Jiang B, Goodman MT, Sibug-Saber M, Cozen W, Liu L, Lynch CF, Wentzensen N, Jordan RC, Altekrise S, Anderson WF, Rosenberg PS, Gillison ML (2011) Human papillomavirus and rising oropharyngeal cancer incidence in the United States. J Clin Oncol 29: 4294-4301.

Dauphin M, Barbe C, Lemaire S, Nawrocki-Raby B, Lagonotte E, Delepine G, Birembaut P, Gilles C, Polette M (2013) Vimentin expression predicts the occurrence of metastases in non small cell lung carcinomas. Lung Cancer 81: 117-122.

Fakhry C, Westra WH, LI S, Cmelak A, Ridge JA, Pinto H, Forastiere A, Gillison ML (2008) Improved survival of patients with human papillomavirus head and neck squamous cell carcinoma in a prospective clinical trial. J Natl Cancer Inst 100: 261-269.

Frederick BA, Helfrich BA, Coldren CD, Zheng D, Chan D, Bunn Jr PA, Raben D (2007) Epithelial to mesenchymal transition predicts gefitinib resistance in cell lines of head and neck squamous cell carcinoma and non-small cell lung cancer. Mol Cancer Ther 6: 1683-1691.

Gabbiani G, Kapanci Y, Barazzone P, Franke WW (1981) Immunochemical identification of intermediate-sized filaments in human neoplastic cells. A diagnostic aid for the surgical pathologist. Am J Pathol 104: 206-216.

Graves CA, Abboodi FF, Tomar S, Wells J, Pirisi L (2014) The translational significance of epithelial-mesenchymal transition in head and neck cancer. Clin Transl Med 3(1): 60 Ecollection.

Hammarstedt L, Lindquist D, Dahlstrand H, Romanitan M, Dahlgren LO, Joneberg J, Creson N, Lindholm J, Ye W, Dalianis T, Munck-Wikland E (2006) Human papillomavirus as a risk factor for the increase of incidence of tonsillar cancer. Int J Cancer 119: 2620-2623.

Hashibe M, Brennan P, Chuang SC, Boccia S, Castellsague X, Chen C, Curado MP, Dal ML, Daudt AW, Fabianova E, Fernandez J, 
Wunsch-Filho V, Franceschi S, Hayes RB, Herrero R, Kelsey K, Koifman S, La Vecchia C, Lazarus P, Levi F, Lence FF, Mates D, Matos E, Menezes A, McLean MD, Muscat J, Eluf- Neto J, Olshan AF, Purdue M, Rudnai P, Schwartz SM, Smith R, Sturgis EM, Szeszenia-Dabrowska N, Talamini R, Wei Q, Winn DM, Shangina O, Pilarska A, Zhang ZF, Ferro G, Berthiller J, Boffeta P (2009) Interaction between tobacco and alcohol use and the risk of head and neck cancer: pooled analysis in the international head and neck epidemiology consortium. Cancer Epidemiol Biomarkers Prev 18: 541-550.

Hatakeyama H, Mizumachi T, Sakashita T, Kano S, Homma A, Fukuda S (2014) Epithelial-mesenchymal transition in human papillomaviruspositive and -negative oropharyngeal squamous cell carcinoma. Oncol Rep 32: 2673-2679.

Hellner K, Mar J, Fang F, Quackenbush J, Münher K (2009) HPV16 E7 oncogene expression in normal human epithelial cells causes molecular changes indicative of an epithelial to mesenchymal transition. Virology 391: 57-63.

Holzinger D, Schmitt M, Dyckhoff G, Benner A, Pawlita M, Bosch FX (2012) Viral RNA patterns and high viral load reliably define oropharynx carcinomas with active HPV16 involvement. Cancer Res 72: 4993-5003.

Hong AM, Grulich AE, Jones D, Lee CS, Garland SM, Dobbins TA, Clark JR, Harnett GB, Millross CG, O’Brien CJ, Rose BR (2010) Squamous cell carcinoma of the oropharynx in Australian males induced by human papillomavirus vaccine targets. Vaccine 28: 3269-3272.

Huber GF, Züllig L, Soltermann A, Roessle M, Graf N, Haerle S, Studer G, Jochum W, Moch H, Stoeckli SJ (2011) Down regulation of E-Cadherin (ECAD) - a predictor for occult metastatic disease in sentinel node biopsy of early squamous cell carcinomas of the oral cavity and oropharynx. $B M C$ Cancer 11: 217-224.

Jensen DH, Dalbelsteen E, Specht L, Fiehn AMK, Therkildsen MH, Jonson L, Vikesaa J, Nielsen FC, von Buchwald C (2015) Molecular profiling of tumour budding implicates TGF $\beta$-mediated epithelial-mesenchymal transition as a therapeutic target in oral squamous cell carcinoma. J Pathol 236: 506-516.

Joo YH, Jung CK, Sun DI, Park JO, Cho KJ, Kim MS (2012) High-risk human papillomavirus and cervical lymph node metastasis in patients with oropharyngeal cancer. Head Neck 34: 10-14.

Jung AC, Briolat J, Millon R, de Reynies A, Rickman D, Thomas E, Abecassis J, Clavel C, Wasylik B (2010) Biological and clinical relevance of transcriptionally active human papillomavirus (HPV) infection in oropharynx squamous cell carcinoma. Int J Cancer 126: 1882-1894.

Jung YS, Kato I, Choi Kim HR (2013) A novel function of HPV16 E6/E7 in epithelial mesenchymal transition. Biochem Biophys Res Commun 435: 339-344.

Kalluri R, Weinberg RA (2009) The basics of epithelial-mesenchymal transition. J Clin Invest 119: 1420-1428.

Klymkowsjy MW, Savagner P (2009) Epithelial-mesenchymal transition. A Cancer Researcher's conceptual friend and foe. Am J Pathol 174: 1588-1593.

Kojc N, Zidar N, Gale N, Poljak M, Fujs Komlos K, Cardesa A, Höfler H, Becker KF (2009) Transcription factors Snail, Slug, Twist and SIP1 in spindle cell carcinoma of the head and neck. Virchows Arch 454: 549-555.

Kreimer AB, Clifford GM, Boyle P, Franceschi S (2005) Human Papillomavirus types in head and neck squamous cell carcinomas worldwide: a systematic review. Cancer Epidemiol Biomarkers Prev 14: 467-475.

Kwon MJ, Kwon JH, Nam ES, Shin HS, Lee DJ, Kim JH, Rho YS, Sung CO, Lee WJ, Cho SJ (2013) Twist promoter methylation is associated with prognosis in tonsillar squamous cell carcinoma. Hum Pathol 44: 1722-1729.

Lamouille S, Xu J, Derynck R (2014) Molecular mechanisms of epithelialmesenchymal transition. Nat Rev Mol Cell Biol 15: 178-196.

Laurson J, Khan S, Chung R, Cross K, Raj K (2010) Epigenetic repression of E-cadherin by human papillomavirus 16, E7 protein. Carcinogenesis 31: 918-926.

Mani SA, Guo W, Liao MJ, Eaton EN, Ayyanan A, Zhou AY, Brooks M, Reinhard F, Zhang CC, Shipitsin M, Campbell LL, Polyak K, Brisken C, Yang J, Weinberg R (2008) The epithelial-mesenchymal transition generates cells with properties of stem cells. Cell 133: 704-715.
Marur S, D'Souza G, Westra WH, Forastiere A (2010) HPV associated head and neck cancer, a virus-related cancer epidemic. Lancet Oncol 11: 781-789.

Mendelsohn AH, Lai CK, Shintaku P, Fishbein MC, Brugman K, Elashoff DA, Abemayor E, Dubinett St SM, John MA (2012) Snail as a novel marker for regional metastasis in head and neck squamous cell carcinoma. Am J Otolaryngol 33: 6-13.

Mendez MG, Kojima SI, Goldman RD (2010) Vimentin induces changes in cell shape, motility and adhesion during the epithelial to mesenchymal transition. FASEB J 24: 1838-1851.

Pectasides E, Rampias T, Sasaki C, Perisanidis V, Kouloulias V, Burtness B, Zaramboulas T, Rimm D, Fountzilas G, Psyrri A (2014) Markers of epithelial to mesenchymal transition in association with survival in head and neck squamous cell carcinomas (HNSSC). PLoS One 9(4): e94273.

Ragin CC, Taioli E (2007) Survival of squamous cell carcinoma of the head and neck in relation to human papillomavirus infection: review and metaanalysis. Int J Cancer 121: 1813-1820.

Ranieri D, Belleudi F, Mafenta A, Torrisi MR (2015) HPV16 E5 expression induces switching from EGFR2b to EGFR2c and epithelial-mesenchymal transition. Int J Cancer 137: 61-72.

Schrader CH, Kolb M, Zaoui K, Flechtenmacher C, Grabe N, Weber KJ, Hielscher T, Pinkert PK, Hess J (2015) Kallicrein-related peptidase 6 regulates epithelial to mesenchymal transition and serves as prognostic biomarker for head and neck squamous cell carcinomas patients. Mol Cancer 14: 107.

Smith EM, Ritchie JM, Summersgill KF, Klussmann JP, Lee JH, Wang D, Haugen TH, Turej LP (2004) Age, sexual behavior and human papillomavirus infection in oral and oropharyngeal cancers. Int J Cancer 108: $766-772$

Syrjanen K, Syrjanen S (2013) Detection of human papillomavirus in sinonasal carcinoma: systematic review and meta-analysis. Hum Pathol 44 983-991.

Thiery JP (2002) Epithelial-mesenchymal transition in tumour progression. Nat Rev Cancer 2: 442-454.

Umbrett C, Flanjak J, Weiss C, Erben P, Aderhold C, Faber A, Stern-Straeter J, Hoermann K, Schultz JD (2014) Incomplete epithelial-mesenchymal transition in p16-positive squamous cell carcinoma cells correlates with $\beta$-catenin expression. Anticancer Res 34: 7061-7070.

Wakisaka N, Yoshida S, Kondo S, Kita M, Sawada-Kitamura S, Endo K, Tsuji A, Nakanish Y, Murono S, Yoshizaki T (2015) Induction of epithelial-mesenchymal transition and loss of podoplanin expression are associated with progression of lymph node metastases in human papillomavirus-related oropharyngeal carcinoma. Histopathology 66 : 771-780.

Yu MA, Kiang A, Wang-Rodriguez J, Rahimy E, Haas M, Yu V, Ellies LE, Chen J, Fan JB, Brumund KT, Weisman RA, Ongkeko WM (2012) Nicotine promotes acquisition of stem cell and epithelial-to-mesenchymal properties in head and neck squamous cell carcinoma. PLoS One 7(12): e51967.

Zeisberg M, Neilsson EG (2009) Biomarkers for epithelial-mesenchymal transitions. J Clin Invest 119: 1429-1436.

Zhang J, Cheng Q, Zhou Y, Wang Y, Chen X (2013) Slug is a key mediator of hypoxia induced cadherin switch in HNSSC: correlations with poor prognosis. Oral Oncol 49: 1043-1050.

Zhao Z, Ge J, Sun Y, Tian L, Lu J, Liu M, Zhao Y (2012) Is E-cadherin immunoexpression a prognostic factor for head and neck squamous cell carcinoma (HNSSC)? A systematic review and meta-analysis. Oral Oncol 48: 761-767.

Zidar N, Gale N, Kojc N, Volavsek M, Cardesa A, Alos L, Höfler H, Blechschmidt K, Becker KF (2008) Cadherin-catenin complex and transcription factor Snail-1 in spindle cell carcinoma of the head and neck. Virchows Arch 453: 267-274.

This work is published under the standard license to publish agreement. After 12 months the work will become freely available and the license terms will switch to a Creative Commons AttributionNonCommercial-Share Alike 4.0 Unported License. 